bacilli, would leave little room for doubt on this score. The absence of any previous chronic disease of the lung should preclude the existence of bronchiectasis or abscess.

In conclusion, we may affirm the existence of a subacute lobar pneumonia distinct from the acute classical type, characterised by a tendency to fibrous and necrotic changes in the lung. The indurative process may be mainly or exclusively interstitial, it may be represented wholly or in part by organisation of an alveolar exudation, or it may comprise both of these lesions. It is possible that these anatomical differences imply a corresponding difference in etiology; but further analysis is not as yet in our power, and, for clinical purposes, both forms nay be included under the title "indurative pneumonia," which indicates the characteristic feature common to each.

\section{SCIENTIFIC STUDY OF THE CONDITION OF CHILDREN IN SCHOOLS.}

By FRANCIS WARNER, M.D.LoND., F.R.C.P.ENG., PHYSICIAN TO THE LONDÓN HOSPITAL, AND LECTURER ON MATERIa MEDICA AND THERAPEUTICS AND ON BOTANY.

I PROPOSE to consider the possible value of accurate observation of facts seen in children in schools, as a means of aiding the solution of educational problems and assessing the value of educational work and certain possible means of improving it. It is needless to argue that public benefit has resulted from the employment of scientific methods in connexion with sanitation, food supply, manufacture, travelling, \&c., while some training in science is now thought necessary for the workers in many trades. In education the teaching of science subjeets is justly valued as a means of producing mental culture. The professions of law, the army, and art do not ignore aid from science; why should not the professional teacher have the benefit of precise knowledge as to the bodily and brain condition of his pupils-the material upon which he works? There is at present but little accurate scientific observation of children in schools, from the point of view of ascertaining their special adaptations to and requirements in education. It remains for our profession to systematise the scientific study of children from the point of view of methods of education, and to put such results before teachers and others responsible for national and private education. In systematising such scientific work as it may be conducted in a large school, without use of the processes of the consulting.room, only methods of observation by sight can conveniently be employed. What signs shall we note, and what relative value is to be assigned to each? Looking upon a body of children as pupils in a school, we would wish to classify them according to their (1) development, (2) nutrition and physical health, (3) brain condition. The grosser forms of low development of the body have many times been ably described by many authorities on imbecility, and the relative value of various defects of skull, the features, \&c., has been fairly determined ; all these may be seen in less degree in school children. I will not dwell further on this group of signs now. As to indications of the brain condition, these may be observed with equal facility by noting the balance and action in the various mobile features and parts of the body. Having previously fully described these signs in works published, $1 \mathrm{I}$ will not attempt even to epitomise them here; they may easily be learned by any observer; but, like all new physical signs, they require some moderate degree of application to recognise them. It is not, however, my desire at present to urge any one system for use in observing children in schools, but to $d$ well on the importance of obtaining scientitic knowledge as to the physical and brain condition of our school population. The late Royal Commission on Blind, Dumb, and Exceptional Children could obtain no body of statistics as to pupils in school, showing how many were defective or feeble in brain, ill-developed, ill-nourished, nervous, mentally dull, or epileptic, \&c. There are 6,000,000 children in schools under the control of the Education Department. How many are

1 The Children : How to Study Them. F. Hodgson, \&9, Farringdonstreet, E.C. Lectures on the Growth and Means of 'Training the Intellectual Faculty. Cambridge C'niversity Press. unfitted for education under the code, who are of low-class make, the percentage of nervous children in the schools, and the distribution of each class? These are questions worthy of investigation. The effects of education and various modes of teaching upon the brains of the children can only be determined by actual observation in the schools. We have large bodies of statistics bearing upon disease, its causation and distribution, and upon pauperism, crime, non-employment, \&c., but there is no body of facts founded upon extended observation of school children showing their condition, and its bearing upon the adult population of the next decade. What is wanted is a careful investigation conducted by observation of the children along definite lines, as well as by inquiry of the teachers. It is only by an extended body of facts obtained in various schools and in different localities in town and country that the average condition of children can be known. I think, from my own observations, that there are more nervous, over-mobile children in London than in northern towns, and fewest cases among the resident pauper schools, while the latter and certified industrial schools contain a high percentage of low conditions of development. At present we have no standard to go by, no average of the conditions we desire to remove. It is desired by all educationists that educational methods should be adapted to the special requirement of the school. The corporate character of a school depends upon the per* centage of the different classes of pupils present; similar methods are not adapted for a school with 10 per cent. nervous children, and 1 per cent. of cranial abnormalities, as compared with another school with $2 \cdot 7$ per cent. nervous children, and 4 'l per cent of cranial abnormalities. (Compare in report quoted Stockwell Practising School and Hanwell National School.) The efforts of a few medical men have produced a report ${ }^{2}$ of the condition of nineteen schools containing about 6000 children; this illustrates, better than any summary I can give here, the kind of information that such inquiry may elicit, and the uses to which it may be put. The study of pathology and clinical diagnosis must precede scientific treatment, and we need some exact knowledge of the condition of samples of the school population before science can take its proper place in directing education, or give due service to the State by advice upon many of the practical problems put forward by the educationist for solution.

Prince of Wales-terrace, Irensington Palace, W.

\section{NOTE ON A CASE IN WHICH THE ILIUM WAS TREPHINED FOR ILIAC ABSCESS.}

Br A. F. MCGILL, F.R.C.S., PROFESSOR OF SURGERY IN THE YORISHHRE COLLEGE.

THE following note shows the good effect which may follow trephining the ilium in suitable cases. Cases of this description are not, however, common. The practice may be expected to be useful when a collection of pus exists under the iliac fascia, and when this collection is circumseribed and limited to the fossa. Pus in this position, when left untreated, will probably pass under Poupart's ligament, and point in the upper part of the thigh extended to the femoral vessels, thus simulating psoas abscess. If they are now opened, or if they burst, a long sinus will be left which will take a considerable time to heal. The direct opening made in the case about to be mentioned apparently avoided this complication, and led to a speedy cure. Possibly this treatment may be of use in cases of abscess in the iliac fossa above the fascia; but I think this is doubtful. The experience of one case is not of much value, but as the treatment adopted is novel, it is given for what it is worth. I am indebted to my house surgeon, Mr. J. J. Mitchell, for the following notes.

C. A-, aged eighteen, was admitted into the Leeds Infirmary, under the care of Mr. McGill, on May 6th, 1889, complaining of pain in the right iliac region and right thigh. In $1884 \mathrm{Mr}$. McGill excised her right hip.joint for disease of long standing. She recovered quickly after the operation,

2 Report of a Committee of the British Pedical Assoriation on observation of Children in Primary Schools. Published by the Cam. bridge Cniversity Press. 